\title{
School Libraries and Social Networks
}

\author{
Gino Roncaglia \\ Senior Research Fellow \\ Tuscia University \\ Italy
}

\begin{abstract}
After a brief introduction to social networks, considered as one of the key tools of web 2.0, the paper deals with the possible uses of social networks and social network applications by school libraries. Social networks are widely used by students, and the range of tools available (or to be implemented) within social-networks is steadily growing. Among them, of special interest for school libraries are 'social reading' and content sharing applications. The paper advocates an active use of social network tools and applications by school libraries, and contrasts such an active use with the simple 'placeholder' pages usually implemented both by school and by university libraries.
\end{abstract}

Web 2.0, social networks, social reading, school libraries

My paper will discuss the use of social networks and of 2.0 tools - that is, tools belonging to the so-called web 2.0 - in fostering the mission of school libraries. The paper is divided in three main sections: 1 ) what is web 2.0 ; 2) what activities - among the ones pertaining to school libraries - might be considered as the most relevant in this context and 3) what web tools might be of help, and how. In this third and last section, my attention will be devoted, as the title of the paper suggests, mainly to social networks and to social network applications.

The following is a preliminary version of the text. The final version will be available on the web site of IASL 2009 and in the Open Archive of Tuscia University (http://dspace.unitus.it).

\section{What is web 2.0}

The term 'web 2.0' has no single and definite meaning: It has rather a broad and somehow vague connotation. I dealt elsewhere with its history and scope1, and here I will just summarize the main features that, in my opinion, are at its core. I will do that by proposing a rather dull list of eight key concepts, each of which followed by a short explanation. I do hope that at least some of them will acquire more substance in the third part of my paper, when I will deal with specific web applications.

\footnotetext{
${ }^{1}$ Roncaglia (2007).
} 
1. User Generated Content (UGT). In the early years of the web, content publishing was limited to people and institutions with access to a web server and with the skills required to build a HTML page and upload it. Content Management Systems (CMS), and most specifically blog-oriented, server-based CMS allowing users to easily write and publish their posts, were but the first step toward a new era: an era of easy content production and sharing. Tools and platforms for image sharing (such as Flickr or Picasa), video sharing (such as YouTube), audio sharing (such as podcasts) were further steps in the same direction. The new web is not just a tool for accessing information produced by institutional entities and by power users: it is an environment in which every single user can publish and share self-produced content. UGC is the core of web 2.0, and most of its tools try to address the obvious problems of sheer volume, organization, classification, evaluation, selection, retrieval, social use and preservation of such a huge amount of information.

2. Semantics. The new web is so huge and complex that old-style directories or even plain text-search engines won't allow us to manage, search and retrieve information in an effective way. We need semantics in order to organize, classify and retrieve information. In adding semantics (i.e. metadata) to the new web, we are confronted with two quite different approaches: Formal, XML-based, well-structured ontologies are required in dealing with uniform, authoritative collections of information (archives, libraries, structured texts and corpora...), while informal, bottom-up social tagging might help in dealing with most of the user generated content. Tools allowing for an effective implementation and - whenever possible - integration of those two strategies will be an essential component of the new web.

3. Collaborative filtering. In the new web, users have both the role of producing information and of using it. And their behaviors in selecting, sharing and using content are also information, that can be - and actually is - scrutinized and used. This raises obvious privacy concerns, but at the same time can be of invaluable help in the process of selecting information: by analyzing the behaviors of users 'similar' to us (and of course our own behavior), a web platform can suggest us books, music, films, news... Any user of Amazon knows how refined and effective those suggestions might get, if we allow the platform to gather enough information about us (profiling).

4. RSS Feeds. The name is technical, but the idea is simple. The books I read - or rather the metadata describing them -, the music I listen to, the images I publish on Flickr or Picasa, the posts I publish on my blog, the short descriptions of what I am doing that I write on social networks such as Twitter or Facebook - in a word, any kind of reasonably uniform content being released over time - can be organized in structured feeds of information, that can freely flow and move from an application to another, from a web page to another. It is difficult to underestimate the importance of RSS feed for the new web. The very idea of gathering in a feed all kinds of different activities of a single user, and of sharing this feed with the user's friends, is at the core of social networks.

5. Embedding, syndication, reuse, mash-up. RSS feed allows for an easy syndication (in its most common translation, RSS stands for Really Simple Syndication) and reuse of flows of information. However, even single pieces of information (an image, a 
video, an audio file) can be easily reused in different web pages. In web 1.0 we did this through links (only in the case of images it was easy - if not always legal - to incorporate in a page images taken from different pages on different web servers). In the new web, we have tools allowing for the direct embedding of all kinds of web content. This means that a web 2.0 page is not just a static, self-enclosed entity: it can be the result of collecting and aggregating content drawn from different web platforms, and ready to be 'taken away' and reused elsewhere, by ourselves or by other users. While web 1.0 was a restaurant based on fixed, pre-arranged menus, web 2.0 is a take away. And not just any take-away: one in which we might want to mix Chinese noodles with Indian Chicken Masala, Italian ice cream and French wine. The new web platforms must thus be able not just to talk to each other, but to actively exchange content, gathering and aggregating it (mash-up).

6. Social networks are the killing application of the new web. In generating content and sharing it, in exchanging messages and information, users establish relations among themselves and with the very information they produce and gather. Such relations - as well as real-life relations seeking a virtual counterpart in the new virtual environments - are in turn information, valuable information that we want to use and profit from (collaborative filtering being but one example of this process). Social networks are the tools of choice to collect, share and put to work that peculiar kind of information constituted by both user-to-user relations and user-to-content relations. This, of course, might be a rather abstract explanation of social networks - a more concrete one would describe them in terms of a collection of users' profiles, each of which includes references to the network of 'friends' of that user, and might embed content (audio, video, news) that the user has either produced or selected. We will further discuss social networks in the third section of this paper, but I am quite confident that most of you are familiar enough with social networks such as Facebook to make sense even of this rather sketchy and abstract description².

7. WebApps, page interaction, Ajax. The web was born as a tool for publishing content produced elsewhere, and not as a tool for actively interacting with and for producing and manipulating content. Accordingly, web browsers were simply clients used to request and receive information from a web server, not a sort of operating system capable of 'running' web based applications. However, we soon discovered that gathering and presenting information was not enough: we need interaction. The idea of web-based applications, embedded in web pages and ready to be used through our browser and inside its window, is another of the key element of the new web. Ajax is the new tool of choice in this field (and a remarkable improvement over the simple use of JavaScript, VBscript, ASP); this is not the place to discuss it, but it is useful to remember that - when asked about web 2.0 - a web programmer would probably mention Ajax as its main tool.

\footnotetext{
${ }^{2}$ A good collection of references on social networks and their use within a school library context is available at http://webtools4u2use.wikispaces.com/Social+Networks, one of the pages of the useful WebTools4UToUse wiki, created for school library media specialists by Dr. Donna Baumbach and Dr. Judy Lee, University of Central Florida.
} 
8. Web design. For most users, the expression 'web 2.0' has also a very visual connotation, made of large and colorful icons and of a simple design oriented to mainly visual rather than only verbal communication. We will not deal here with this aspect of the new web, but again it might be useful to mention it: web design is after all a central feature of any web page or site, and an effective communication with our users requires good, sound and usable web design.

\section{Three tasks for school libraries}

School libraries have a number of strictly interrelated but distinct tasks to fulfill. Among them, three seem to be of special relevance: 1) information literacy; 2) active promotion of reading and researching, and 3) support for learning and educational activities. Such a support should be provided both to teachers and to learners (I prefer to use the term 'learners' rather than 'students' or 'pupils', since I firmly believe that schools and school libraries - as well as universities and university libraries - have a relevant role to play in promoting lifelong learning, and should find new ways to address not just the educational needs of their students, but part of the lifelong learning needs of their parents and families as well).

While I wouldn't dare to suggest that the three tasks above are sufficient to define the mission of school libraries, I think it is quite safe to say that they should be necessary and primary components of such a definition. I will not discuss them in detail, both for lack of time, and because they have been and will be addressed with greater competence in many of the papers delivered here, but I would like to advance some further considerations on the third one.

Schools and universities are the undisputed core of our learning system, and their activity is (or has traditionally been) mainly devoted to formal learning. And there are good reasons and sound arguments in favor of highly structured and organized educational systems: detailed curricula, and reasonably standard and uniform teaching and testing practices, help in granting everybody the same learning opportunities, in selecting and promoting good practices, in assessing learning results.

But we do know that formal learning is not enough, and that informal learning is probably even more important. Despite the time that each and every of us spent in schools and universities, much of what we know - and much of the motivation that got us to learn what we know - is the result of informal learning. Providing an environment capable of fostering and promoting rich and effective informal learning practices is, in my opinion, a key element in achieving learning success, even within schools and universities.

I will not enter the debate concerning the differences between informal and nonformal learning. For my purposes here, it will be enough to stress that many learning practices and situations that are perceived as informal from the point of view of the learner, might well be planned and organized from the point of view of a teaching agent. A good example is provided by institutional awareness campaigns: the TV or radio ads explaining the health risks of smoking are tools for informal learning from the point of view of their audience, but might and should be carefully planned by the institution organizing the campaign.

This is just one among many possible examples of 'organized informal learning'; we could describe such situations as a sort of 'learning trap': the learner is driven into a framework offering a (hopefully attractive and compelling) learning opportunity, without requiring her or him to plan or even to know that in advance. 
The new web, and more specifically social networks, constitute an ideal context for planning and implementing informal learning: they fulfill the main requirement for an effective learning environment - offering the possibility of a rich and interactive multichannel communication - and most of our learning targets are already there, eager to explore and interact with whatever the new environment provides them.

Furthermore, I am convinced that school libraries have the ideal skills for planning and disseminating web-based informal learning. In the next section, I will try to explain why it is so, and to discuss some of the tools that can be used.

\title{
Social networks and school libraries
}

There is no lack of statistics on the amazing penetration of social networks. According to Nielsen’s report “Global Faces and Networked Places” 2009,

\begin{abstract}
Social Networking has been the global consumer phenomenon of 2008. Two-thirds of the world's Internet population visit a social network or blogging site and the sector now accounts for almost $10 \%$ of all Internet time. 'Member Communities' has overtaken personal Email to become the world's fourth most popular online sector after search, portals and PC software applications.
\end{abstract}

The story is consistent across the world, 'Member Communities' has taken a foothold in every major market from $50 \%$ of the online population in Switzerland and Germany to $80 \%$ in Brazil. Facebook has become the largest player on the global stage, dominant in many countries, yet localized offerings have won the day in many others.

However, the growth in popularity of social networks - and the resultant broadening audience - is only half the story. The staggering increase in the amount of time people are spending on these sites is changing the way people spend their time online and has ramifications for how people behave, share and interact within their normal daily lives. ${ }^{3}$

There is probably no need to say that such statistics are still more impressive when the focus is on the so-called 'Generation Y': as early as 2007, an astounding 96\% of all American on-line population aged 9-17 was using social network tools4. Time spent on social networks is growing three times faster than the overall Internet rate, and the data concerning the most important social network5, Facebook, are still higher.

Social networks, therefore, are the place to be if we want to implement web-based informal learning. And in doing that we can profit from three invaluable tools: RSS feeds, content embedding and social network applications.

But let's start from the very idea of social networks. In the early days of web 2.0, it was quite common to distinguish between relation-oriented social networks (such as

\footnotetext{
${ }^{3}$ Nielsen Company (2009).

${ }^{4}$ Grunwald Associates National study; cf. http://www.trendsspotting.com/blog/?p=165. he research does include e-mail among social network tools, but the impact of this should not be overestimated: Generation $\mathrm{Y}$ and $\mathrm{Z}$ consider e-mail as a tool of the past, and in 2009 Boston College stopped distributing e-mail addresses to incoming freshmen (http://socialnomics.net/2009/08/11/statistics-show-social-media-is-bigger-than-you-think/).

${ }^{5}$ While it is safe to consider Facebook as the most important social network on a global scale, China's QZone might have a larger number of users: over 300 million, with 150 million updating their account at least once a month (http://www.web2asia.com/2009/02/24/the-world-s-largest-online-social-network-qzone). As of August 2009, Facebook declares more than 250 million active users, with more than 120 million logging on at least once each day.
} 
MySpace), where the main aim is to build upon personal contacts and relations between users and to foster them, and content-oriented social networks (such as YouTube or Flickr), mainly devoted to host and share user generated content.

Facebook successfully challenged this idea. Born as a relation-oriented social network, it owes much of its success to the very tidy and effective implementation of a simple idea: the stuff of which personal relations are made of is information; therefore, implementing tools for sharing information and user generated content is a key element of the mission of a relation-oriented social network. The two models - relation oriented and content oriented social network - should (and did) collapse into a single one.

Embedding, feeds and WebApps are the tools used to reach this goal. Content embedding and RSS feeds have been dealt with in the first section of this paper: as we already know, they are both used to 'move' content (text, images, audio, video) from one site to another, allowing for content mash-up. From the point of view of a social network, this makes it possible to aggregate and embed in the page of a given user the streams of posts from the user's blog, her or his images from an image sharing platform such as Flickr or Picasa, her or his videos from a video sharing platform such as YouTube, and so on.

Let us try immediately to picture this process of aggregation from the point of view of a school library. In this exercise, we will use Facebook as our social network of choice, because of its being both the most widely used and the most powerful in allowing content aggregation, but the same principles would apply to other social networks. A number of school libraries already have a Facebook page. Unfortunately, most of them use their page just as a sort of place-holder: apparently, the message they intend to convey is just that of 'being there': our users are on Facebook, and we are on Facebook too, we are cool, and you can enroll among our supporters ("became a fan”).

This means that the Facebook page is not fulfilling its primary goal: aggregating and embedding information (both by means of web feed and by means of direct upload), and allowing for its reuse. The school library might have a blog, or a web site powered by a RSS enabled content management system, or an OPAC that generates the RSS feed of recent acquisitions... why not using the page as an aggregator for such information? And, even if these tools are not available, they probably are available at a close-by library or institution, waiting to be syndicated and reused.

What is striking is that the idea of virtual reference desk is by now - or should be by now - quite familiar to a library (and the idea of a learning-oriented virtual reference desk is or should be familiar to a school or university library). However, virtual reference desks are often still conceived as a mainly static collection of links. Feeds and embedding allow for a rethinking of the very idea of virtual reference desk: to the static collection of links to other resources, we may now add a dynamic flow of relevant content and information, selected, aggregated and shared via social networks. This might be of great significance in the context of a school library, where information literacy is a primary goal, and the use of simple tools for content selection and aggregation might help in achieving it.

Content selection and syndication, by the use of embedding and feeds, might thus be a first step in making the social network page of a school library an useful tool and not just a placeholder. And WebApps, and more specifically social-reading oriented WebApps, might be the second.

Most social networks - Facebook being again probably both the best known and the most useful example - allow for the free development and use of WebApps: small, interactive web applications that can be easily embedded in the user's page. For sure, most WebApps could be considered, from our point of view, totally useless if not deplorably frivolous: virtual birthday gifts, vampire bites, and the like. However, a 10-minutes search 
within the thousands of available Facebook applications should be enough to discover way more interesting and useful tools.

A first, obvious pick would be social reading applications. Before considering them , let us briefly introduce the concept of web-based social reading and of social reading platforms. The idea is to allow users to build a personal bookshelf, in which it is possible to include (and differentiate) books that the user just owns, books she or he did actually read, books she or he is reading, and finally books that the user doesn't own but would like to read. A book is represented by its cover image, allowing for very 'visual' bookshelves, and every book may be reviewed and rated by the user. Collaborative filtering is then applied to the data collected by the platform, thus generating both suggestions for new books to read ("among the users with bookshelves 'close' to yours in titles and ratings, such and such books, that are not in your bookshelf, are often included and highly rated. Therefore, you might like them too"), and suggestions of new users to connect with (those having bookshelves 'close' to yours). Forums to discuss books, feed RSS for each user's bookshelf and links from every single book to on-line bookstores are usually included among the tools offered by social reading platforms.

At the moment, there are 6 or 7 players in the field of social reading platforms: the best known are Anobii, quite popular in Europe, Shelfari, bought by Amazon in August 2008, GoodReads, possibly the most features-packed6, LibraryThing, Living Social Books (aka Visual Bookshelf) and weRead (formerly iRead). All of them offer small Facebook applications, that allow the user to display the most recent readings or acquisitions in her or his Facebook page, and automatically add information on all the bookshelf-related activities to the user's Facebook feed.

Visual Bookshelf (more than 900.000 monthly active users) and WeRead (almost 400.000 monthly active users) seem to be the applications of choice among Facebook members, GoodReads being the only other social reading Facebook application with more than 100.000 monthly active users.

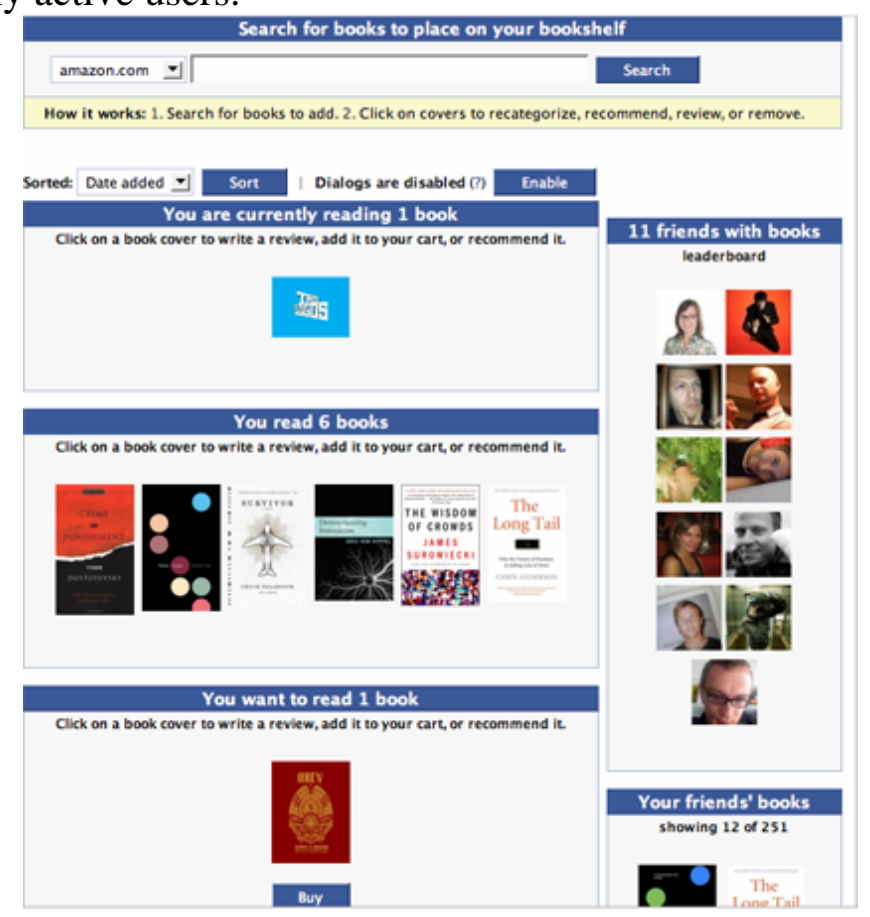

Figure 1 - The Visual Bookshelf (aka Living Social: Books) Facebook application

\footnotetext{
${ }^{6}$ Cf. http://www.kenwohlrob.com/2009/02/goodbye-shelfari-library-thing-and.html
} 
Our purpose here is not to review social reading applications or to compare their features, but rather to suggest that such applications might be of invaluable help for a school library. The library could add one of them to its Facebook page, using it to display new acquisitions, or book suggestions related to school activities or to breaking news. And the library could foster the use of such applications among its users, encouraging them to share their readings, their book reviews, their requests. The very idea of social reading is a powerful tool for the active promotion of reading, and promoting the use of 'intelligent' web applications in the context of social networks is by itself part of a web 2.0-aware strategy for information literacy. A strategy that takes place in a virtual environment - Facebook - where most of our users are probably already present and active; furthermore, a strategy that is in perfect agreement with the idea of 'organized informal learning' discussed above.

However, social reading applications are not the only ones that could be profitably used by a school or university library. Here, I can just mention social network applications such as iRemember7, connected to the well known history-oriented social repository Footnote, that allows users to search and share historical documents and documents related to their family history. Or to applications helping to manage working groups, such as Study Groups, that "lets you quickly and easily collaborate with your classmates and plan out homework for your courses" allowing to "create to-do lists and track who's responsible for what; Schedule and agree to meetings; Ask questions about this week's assignment; Share notes and files in one place; Create a public Study Group to collect the thoughts and ideas of users around the world on a given subject; Create, edit, and collaborate on papers and notes"8. Or to document-management applications such as Digital Text 2.09, a Facebook application that "helps you to organize and share your digital texts. You can group your texts into collections, associate them with authors, assign tags and other useful metadata, and add your notes and comments. You can also join groups, see what your friends are reading, and share your texts and annotations.”10 Facebook apps are also available for document-sharing platforms such as Scribd or Issuu, or for presentation-sharing platforms such as Slideshare.

I won't even mention the tools for sharing YouTube vids or Flickr images, well known to any user of social network platforms and usually features of the platform itself. Nor will I mention the many specific library oriented applications (many of them allowing the access to library OPACs and services from within Facebook): mostly 'local' tools with a limited users base11, and probably, from our point of view, less useful than social reading and content sharing applications. However, they too are part of the overall picture.

My purpose here was to stress the potential benefits for school and university libraries of an active use of social networks, including content and information sharing applications. I have not discussed case studies or already existing practices, since most of them do not involve the use of the kind of tools and applications I wanted to deal with12. Even the Yalsa paper on Teens \& Social Networking in School \& Public Libraries: A Toolkit for Librarians

\footnotetext{
${ }^{7}$ http://www.facebook.com/apps/application.php?id=58547631756\&ref=search

${ }^{8}$ From the Facebook page of the application, http://apps.facebook.com/apps/application.php?id=3978168062.

${ }^{9}$ http://dtext2.org/main/welcome; cf. also Rodgers, J., Sinclair S. (2008).

${ }^{10}$ From the home page of the application, at http://dtext2.org/main/welcome

11 Even the Worldcat Facebook application has at the moment less than 500 monthly active users (cf. http://www.facebook.com/apps/application.php?id=7644880307\&ref=appd)

${ }^{12}$ For the same reason, and despite their interest, I will not discuss here the results of the Valparaiso University survey on Facebook and university libraries included in Connell (2009).
} 
\& Library Workers13 - while providing a lot of useful information and relevant comments somehow misses the point in suggesting to

Build a library MySpace or a librarian Facebook space with teens. Have teens meet to plan the space, including what it should look like and include. Work with them to build the site, and develop guidelines for blogging, commenting, and making friends on the site. As a part of this project, talk with teens about how to decide whether or not to accept those who want to befriend them on MySpace or Facebook. Add value to your MySpace or Facebook presence through links to online safety and library resources. Make it possible for teens to add your catalog search on their MySpace or Facebook accounts. ${ }^{14}$

The focus here seems to be on the educational experience involved in building together with the users - a Facebook page for the library (wouldn't it be more useful to help the users in effectively planning their own pages, making them well-structured, informative and privacy-aware?), rather than on actively using the social network as a tool for dynamically aggregating and sharing content and information. The only reference to web applications concerns the use of OPAC-search widgets: tools that - if properly explained might well be of some utility as a first step in introducing social network users to the world of full-featured OPACs, but that do not allow for the kind of active information sharing possible through the use of social readings and content sharing applications.

School and University libraries - as well as research and teaching institutions should, in my opinion, be active and full-fledged agents in the world of social networks, and not just names within placeholder pages. They should not collect 'fans', they should dynamically aggregate and share useful content and information, and help users in doing the same.

\section{References}

Connell, R.S. (2009). Academic Libraries, Facebook and MySpace and Student outreach: a survey of student opinion. In: Portal: libraries and the academy, vol. 9, n. 1 p. 25-36.

Nielsen Company (2009). Global Faces and Networked Places. A Nielsen report on Social Networking's New Global Footprint. The report is available at http://blog.nielsen.com/nielsenwire/wpcontent/uploads/2009/03/nielsen_globalfaces_mar09.pdf.

Rodgers, J., Sinclair S. (2008). Digital Texts 2.0. Towards Social Networking of Texts. Poster available at http://www.creativecreature.ca/blog/wp-content/digital-texts-poster.jpg.

Roncaglia, G. (2007). Gli strumenti del nuovo web e l'organizzazione della ricerca in campo umanistico, to be published in the proceedings of the conference "Le opere filosofiche e scientifiche. Filosofia e scienza tra testo, libro e biblioteca", Lecce, 7-8 febbraio 2007. Full text available at http://dspace.unitus.it/handle/2067/433.

Young Adult Library Services Association (2008). Teens \& Social Networking in School \& Public Libraries: A Toolkit for Librarians \& Library Workers. Chicago. Full text available at http://www.ala.org/ala/mgrps/divs/yalsa/profdev/SocialNetworkingToolkit_Jan08.pdf.

\section{Statement of Originality}

This statement certifies that the paper above is based upon original research undertaken by the author and that the paper was conceived and written by the author(s) alone and has not been published elsewhere. All information and ideas from others are referenced.

\footnotetext{
${ }^{13}$ Young Adult Library Services Association (2008).

${ }^{14}$ Young Adult Library Services Association (2008), p. 9.
} 